Bull. Chem. Soc. Ethiop. 2013, 27(1), 117-124.

Printed in Ethiopia

ISSN 1011-3924

DOI: http://dx.doi.org/10.4314/bcse.v27i1.12

(c) 2013 Chemical Society of Ethiopia

\title{
CYCLIC VOLTAMMETRY AND REDUCTION MECHANISTIC STUDIES OF STYRYLPYRYLIUM PERCHLORATES
}

\author{
Jean Claude W. Ouédraogo ${ }^{1}$, Issa Tapsoba ${ }^{1}$, Boubié Guel ${ }^{2}$, Faustin Sié Sib ${ }^{1}$ and Yvonne Libona \\ Bonzi-Coulibaly $^{1 *}$ \\ ${ }^{1}$ Laboratoire de Chimie Organique: Structure et Réactivité, UFR/SEA, Université de \\ Ouagadougou; 03 BP 7021 Ouagadougou 03, Burkina Faso \\ ${ }^{2}$ Laboratoire de Chimie-Physique et d'Electrochimie, UFR/SEA, Université de Ouagadougou, \\ 03 BP 7021 Ouagadougou 03, Burkina Faso
}

(Received May 26, 2011; revised July 05, 2012)

\begin{abstract}
The reduction and oxidation potentials of methylated 4-styrylpyrylium and 6-styrylpyrylium perchlorates have been evaluated using cyclic voltammetry, in comparison to their non-methylated derivatives values. The reduction peak of all studied compounds remained chemically irreversible. The presence of the electron-donating methyl group on pyrylium ring leads to a shift of the styrylpyrylium perchlorates reduction potential towards cathodic values. Kinetic studies on platinum electrodes based on the variation of the peak potential at different scan rates and upon substrate concentrations confirm, in another way, the mechanism of electron transfer.
\end{abstract}

KEY WORDS: Styrylpyrylium perchlorates, Cyclic voltammetry, Reduction potential, Kinetic study

\section{INTRODUCTION}

Pyrylium cations are oxonium ions widely used as reactive intermediates in many organic syntheses [1,2]. Their cationic nature makes them excellent electron acceptors and gives them interesting properties useful in various applications. They are used as antitumor agents [3], laser dyes [4], sensitizers in photographic materials [5] and semiconductors [6]. The pyrylium salts present potential applications as fluorescent probes for metals detection, adsorption of iodide anions [7] and homogeneous photocatalysts for the degradation of organic pollutants, such as phenolic compounds [8,9] and pesticides [10]. All these cited properties and the physicochemical characteristics of pyrylium salts are dependant to the substituents on the pyrylium ring. Electrochemical signal measurement is an advanced analytical technique for pyrylium cation study. The electrochemistry of pyrylium (e.g. 2,4,6-triphenylpyrylium) salts in protic and aprotic solutions is well understood and reported in the literature [11, 12]. In general, it is admitted that pyrylium cation submitted to reduction in aprotic solvent, evolves according to a one-electron transfer to lead to a pyranyl radical which can evolve through dimerization process to give a bispyranic product [12-14]. However, the pyranyl radical generated after the first electron transfer exhibits a second reduction peak yielding a pyranyl anion [15, 16]. Although abundant electrochemical studies on a large series of pyrylium salts exist, few reports described electrochemical properties of styrylpyrylium cation. Styrylpyrylium perchlorates can have interesting properties, and these properties will depend on the substituents on the pyrylium ring. In addition, according to our knowledge, there have been no reports on the mechanistic investigation of these compounds by a kinetic approach in an electrochemical study.

We report herein the potential reduction values obtained by cyclic voltammetry of two methylated styrylpyrylium perchlorates in comparison with the potential reduction values of non-methylated styrylpyrylium perchlorates previously determined by Guel et al. [17]. The substitution effect on the reduction potential values is discussed. In addition, we employed

*Corresponding author. E-mail: bonziy@univ-ouaga.bf 
kinetic study in electrochemistry, based on the effect of substrate concentration and scan rate on the reduction peak potential, to determine the real reduction mechanism of the styrylpyrylium perchlorates derivatives.

\section{EXPERIMENTAL}

All the styrylpyrylium salts investigated (Scheme 1) are synthesized according to the method described in the literature [18]. The compound 1e with three phenyl groups was used as a model compound.<smiles>[R]c1cc([R])c([R])c([R])c1[R]</smiles>

\begin{tabular}{|c|c|c|c|c|}
\hline Compound & $\mathbf{R}_{1}$ & $\mathbf{R}_{2}$ & $\mathbf{R}_{3}$ & $\mathbf{R}_{4}$ \\
\hline 1a & $\mathrm{C}_{6} \mathrm{H}_{5}$ & $\mathrm{H}$ & $\mathrm{CH}=\mathrm{CH}-\mathrm{C}_{6} \mathrm{H}_{5}$ & $\mathrm{C}_{6} \mathrm{H}_{5}$ \\
\hline $1 \mathrm{~b}$ & $\mathrm{C}_{6} \mathrm{H}_{5}$ & $\mathrm{CH}_{3}$ & $\mathrm{CH}=\mathrm{CH}-\mathrm{C}_{6} \mathrm{H}_{5}$ & $\mathrm{C}_{6} \mathrm{H}_{5}$ \\
\hline $1 \mathrm{c}$ & $\mathrm{C}_{6} \mathrm{H}_{5}$ & $\mathrm{H}$ & $\mathrm{C}_{6} \mathrm{H}_{5}$ & $\mathrm{CH}=\mathrm{CH}-\mathrm{C}_{6} \mathrm{H}_{5}$ \\
\hline 1d & $\mathrm{C}_{6} \mathrm{H}_{5}$ & $\mathrm{CH}_{3}$ & $\mathrm{C}_{6} \mathrm{H}_{5}$ & $\mathrm{CH}=\mathrm{CH}-\mathrm{C}_{6} \mathrm{H}_{5}$ \\
\hline 1e & $\mathrm{C}_{6} \mathrm{H}_{5}$ & $\mathrm{H}$ & $\mathrm{C}_{6} \mathrm{H}_{5}$ & $\mathrm{C}_{6} \mathrm{H}_{5}$ \\
\hline
\end{tabular}

All the experiments were performed in acetonitrile purchased from Sigma. It was dried over anhydrous sodium sulfate $\left(\mathrm{Na}_{2} \mathrm{SO}_{4}\right)$ and distilled. A solution of $0.1 \mathrm{M}$ tetrabutylammonium hexafluorophosphate $\left(\mathrm{Bu}_{4} \mathrm{NPF}_{6}\right)$ in acetonitrile was used as a supporting electrolyte. $\mathrm{Bu}_{4} \mathrm{NPF}_{6}$ was purchased from Aldrich and used without further purification. The acetonitrile-electrolyte support containing the substrate in the concentration of $10^{-3} \mathrm{M}$ was purged with nitrogen gas for 15 min. All experiments were carried out at room temperature.

Cyclic voltammetry was performed using a Potentiostat type Solartron 1208B coupled with a computer equipped with a CorrWare software. In this part, experiments were carried out with a standard three-electrode system. The reference electrode was the $\mathrm{AgNO}_{3} 0.1 \mathrm{M} / \mathrm{Ag}$ system $(0.56 \mathrm{~V}$ vs NHE); the working electrode was a platinum disk type of $5 \mathrm{~mm}$ of diameter and platinum wire was used as the auxiliary electrode.

For the kinetic study, cyclic voltammetry was performed using a portable PalmSens Potentiostat/Galvanostat (Palms Instrument, Netherlands). The experiments were carried out with a standard three-electrode system consisting of a $\mathrm{Ag} / \mathrm{AgCl} / 0.1 \mathrm{M} \mathrm{KCl}(0.29 \mathrm{~V}$ vs $\mathrm{NHE})$ as a reference electrode, an platinum wire as an auxiliary electrode and a platinum disk with a diameter of $2 \mathrm{~mm}$ as a working electrode. 


\section{RESULTS AND DISCUSSION}

\section{Electrochemical reduction of methylstyrylpyrylium perchlorates}

Figure 1 shows the voltammetric behavior of the styrylpyryliums $\mathbf{1 b}$ and $\mathbf{1 d}$ investigated in acetonitrile containing $0.1 \mathrm{M}$ of tetrabutylammonium hexafluorophosphate $\left(\mathrm{Bu}_{4} \mathrm{NPF}_{6}\right)$ as the supporting electrolyte. As seen in Figure 1, each reduction curve exhibits one irreversible peak $(-0.61 \mathrm{~V}$ and $-0.69 \mathrm{~V})$ corresponding to one electron transfer to the pyrylium salt.

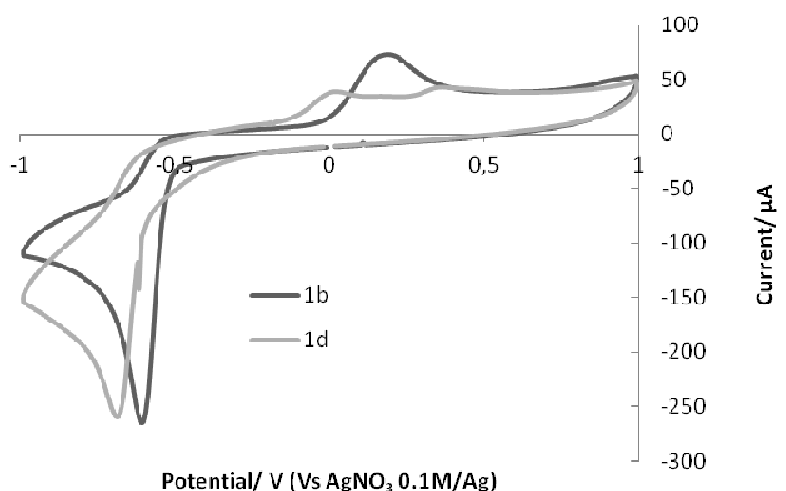

Figure 1. Cyclic voltammograms of $10^{-3} \mathrm{M}$ of $\mathbf{1 b}$ and $10^{-3} \mathrm{M}$ of $\mathbf{1 d}$ in $\mathrm{CH}_{3} \mathrm{CN}+0.1 \mathrm{M} \mathrm{Bu}_{4} \mathrm{NPF}_{6}$. Scan rate: $\mathrm{v}=50 \mathrm{mV} / \mathrm{s}$. Pt electrode $(\Phi=5 \mathrm{~mm})$. Reference electrode: $\mathrm{AgNO}_{3} 0.1$ M/Ag.

The irreversibility of the reduction peak demonstrates the instability of the pyranyl radical generated after the electron transfer. This means that the pyranyl radical evolves according to a fast chemical reaction which is in conformity with the dimerization reaction. The radical is suggested to be located in the double bond and to give a dimer named butane-1,4-diylidene bis$2 H$-pyran derivatives [19].

On the reverse scan, the cyclic voltammetric curves exhibit a single irreversible peak for $\mathbf{1 b}$. This peak is attributed to the oxidation of the formed dimer [19]. The intensity of this wave depends directly on the value of the reverse sweep potential (Figure 2). In fact, no oxidation peak is observed when the scanning potential $\left(\mathrm{E}_{\mathrm{f}}\right)$ is reversed before reaching the reduction peak potential (if $\mathrm{E}_{\mathrm{f}}$ is limited at $-0.5 \mathrm{~V}$ ). This behavior shows that the initial cathodic charge transfer on the pyrylium cation is followed by chemical reaction of the generated radical, as well described in literature $[13,15,17,19]$.

When the scanning potential $E_{\mathrm{f}}$ reaches more negative values, the reduction peak potential value remains constant but the oxidation peak increases in intensity. So the amount of dimer compound formed increases in the solution during the necessary time to reach cathodic values and leading to an increase of their oxidation wave intensity. 


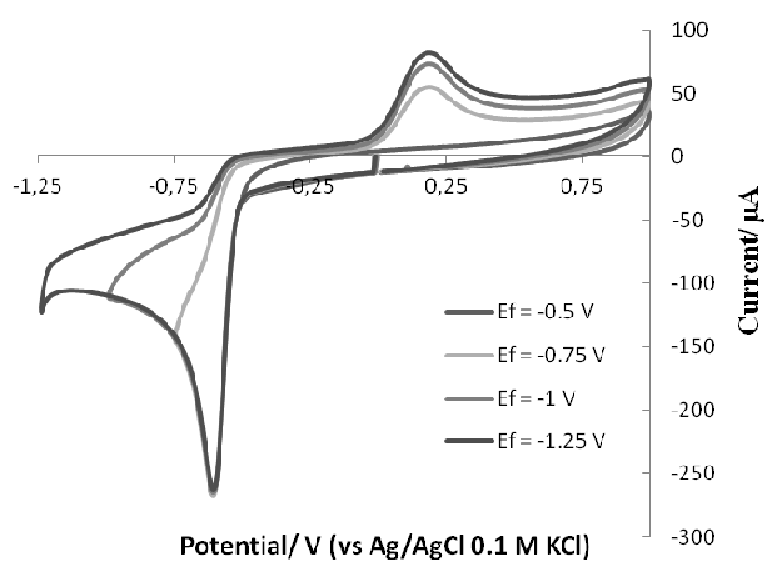

Figure 2. Cyclic voltammograms of $\mathbf{1 b}$ in $\mathrm{CH}_{3} \mathrm{CN}+0.1 \mathrm{M} \mathrm{Bu}_{4} \mathrm{NPF}_{6}$ recorded upon sweep potential $\mathrm{E}_{\mathrm{f}}$. Scan rate: $\mathrm{v}=50 \mathrm{mV} / \mathrm{s}$. Pt electrode $(\Phi=5 \mathrm{~mm})$. Reference electrode: $\mathrm{AgNO}_{3} 0.1 \mathrm{M} / \mathrm{g}$. Concentration: $\mathrm{c}=10^{-3} \mathrm{M}$.

The same behaviour observed on compound $\mathbf{1 b}$ is obtained when the cyclic voltammetry is carried out on the other compounds (1a, 1c and 1d). The electrochemical analysis data are summarized in Table 1.

Table 1. Reduction peak potential of investigated compounds determined by cyclic voltammetry in $\mathrm{CH}_{3} \mathrm{CN}$ $+\mathrm{Bu}_{4} \mathrm{NPF}_{6} 0.1 \mathrm{M}$; Pt electrode $(\Phi=5 \mathrm{~mm})$. Reference electrode: $\mathrm{AgNO}_{3} 0.1 \mathrm{M} / \mathrm{g}$. Scan rate: 50 $\mathrm{mV} / \mathrm{s}$.

\begin{tabular}{|c|c|c|c|c|c|}
\hline Compound & $\mathbf{1 a}^{*}$ & $\mathbf{1 b}$ & $\mathbf{1 c}^{*}$ & $\mathbf{1 d}$ & $\mathbf{1 e}$ \\
\hline $\mathrm{E}_{\mathrm{r}}^{\mathrm{red}}(\mathrm{V}) \mathrm{vs} \mathrm{AgNO}_{3} 0.1 \mathrm{M} / \mathrm{Ag}$ & -0.55 & -0.61 & -0.60 & -0.69 & -0.79 \\
\hline
\end{tabular}

*Value previously reported by Guel et $a l$. [17].

The data given in Table 1 shows that compound 1a presents a weak reduction potential $(-0.55 \mathrm{~V})$ compared to the other compounds. The reduction potential of the methylated styrylpyrylium perchlorates (1b and 1d) are higher than the non-methylated (1a and 1c). This result could be explained by the electron donor effect of the methyl group. Indeed, the presence of a methyl group on the pyrylium ring of $\mathbf{1 b}$ and $\mathbf{1 d}$ decreases the reducible character of the pyrylium salt, and the reduction potentials shift towards cathodic values. The highest value $(-0.79 \mathrm{~V})$ is for the compound 1e bearing three phenyl groups and studied as a model molecule. If one phenyl group of 1e is replaced by a styryl group (1a or 1c) there is an anodic shift of the reduction peak potential. This proves that the styryl group's presence increases the pyrylium reducible character. The styryl moiety acts as an electron-withdrawing group destabilizing the oxonium moiety in a pyrylium cation.

In addition, regarding potential reduction values with compounds 1d compared to compound $\mathbf{1 b}$, the position 6 of the styryl group in the pyrylium ring induces a lower value of the reduction peak potential in agreement with previous data on compound 1c compared to $\mathbf{1 a}$ [17]. Our result confirms that the proximity of the styryl group to the oxonium moiety seems to be the main reason for the decrease of the molecule's reduction behavior. The effects of a styryl 
or methyl group in the pyrylium ring observed in the present electrochemistry study have the same tendency as observed in NMR studies reported previously by Ouédraogo et al. [20].

Kinetic investigation: elucidation of the mechanism of reduction of styrylpyrylium's salts

Scan rate effects. An increase of the scan rate leads to an increase of the peak current and concomitantly to a linear shift of the peak potential towards more cathodic values (Figure $3 \mathrm{a}$ ). However, the reduction peak of all studied substrates remained chemically irreversible.

The slope obtained by linear regression of the $\log$ Ip versus $\log v$ is $c a$. 0.47 (Figure $3 \mathrm{~b}$ ), which corresponds to a diffusion controlled process over this scan rate range as observed for amino aromatic compounds [21].

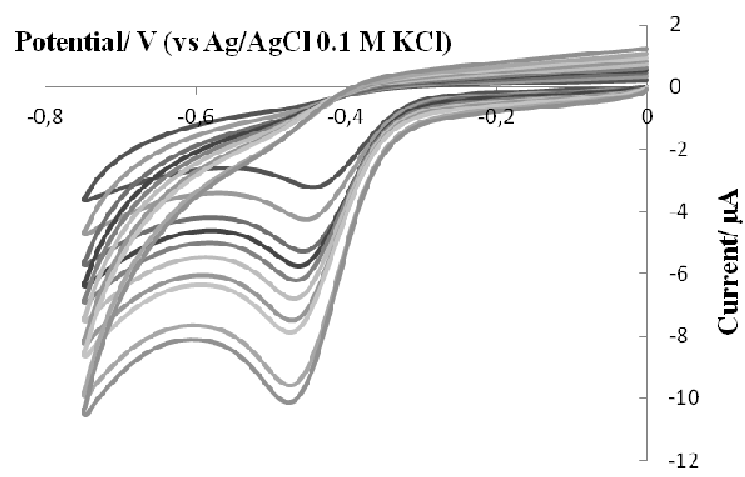

(a)

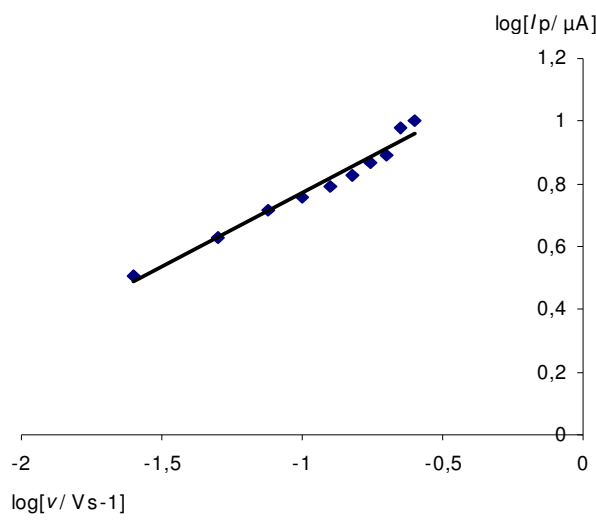

(b)

Figure 3. (a) Cyclic voltammograms of $5 \times 10^{-4} \mathrm{M}$ of $\mathbf{1 d}$ in different scan rate from 25 to 250 $\mathrm{mV} / \mathrm{s}$. (b) The logarithmic relationship of the cathodic peak current vs. scan rate for $1 \mathbf{d}$ in $\mathrm{CH}_{3} \mathrm{CN}+0.1 \mathrm{M} \mathrm{Bu}_{4} \mathrm{NPF}_{6}$ at a platinum disk electrode $(\Phi=2 \mathrm{~mm})$.

The peak potential shifts linearly to cathodic values with the increase of the scan rate. The slope of the Ep versus $\log v$ is ca. $32 \mathrm{mV}$ per decade (Figure 4). The obtained value is in agreement with a fast electron transfer followed by a first order chemical reaction, confirming 
that the rate determining step is the dimerization reaction of the pyranyl radical emerging after the fast electron transfer $[12,15,19]$.

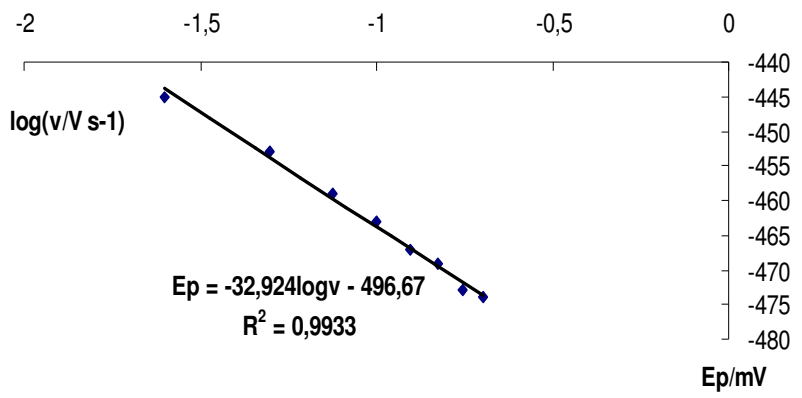

Figure 4. Variation of the reduction peak potential of $\mathbf{1 d}$ in $\mathrm{CH}_{3} \mathrm{CN}+0.1 \mathrm{M} \mathrm{Bu}_{4} \mathrm{NPF}_{6}$ at a platinum disk electrode as a function of the logarithm of the sweep rate. Reference electrode: $\mathrm{Ag} / \mathrm{AgCl} 0.1 \mathrm{M} \mathrm{KCl}$. Concentration: $\mathrm{c}=5 \times 10^{-4} \mathrm{M}$.

Substrate concentration effects. In another series of experiments, the current of the reduction peak increases upon the concentration of the substrate increases (Figure 5a) and the linear representation of the potential peak (Ep) with the $\log$ arithm of the concentration $(\log c)$ shows a slope of $c a .20$ ( Figure 5b).

The linear dependence of the potential peak values $(E p)$, with a slope (ca. 20) obtained above and the irreversibility of the pyrylium cation reduction peak, are in agreement with the fast electron transfer which takes place at the platinum electrode followed by a chemical reaction. According to the literature $[12,19,21]$ and based on the above results observed from kinetic study, the chemical reaction of the radical pyranyl electrogenerated from pyrylium cation after electron transfer, is a dimerization reaction between radical pyranyl as illustrated in the following mechanism (Scheme 2).

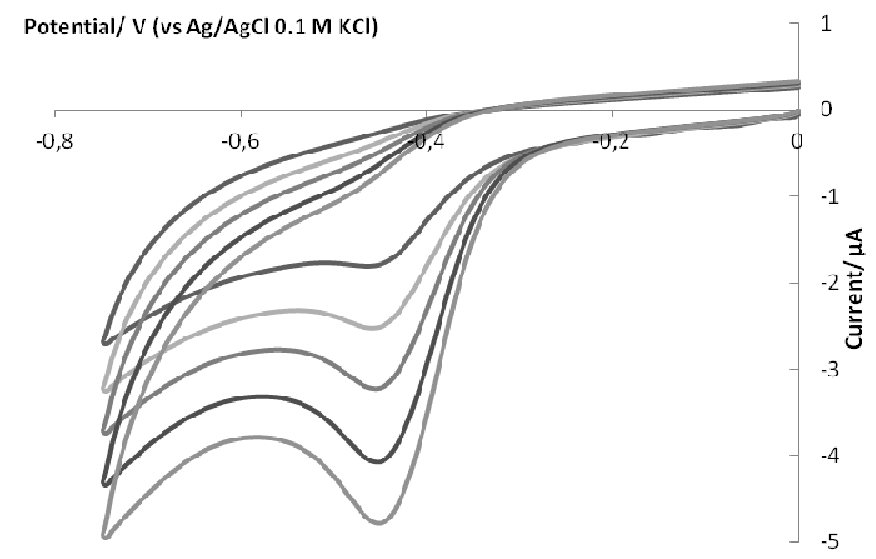

(a) 


\section{$\operatorname{lng}(\mathbf{c} / \mathbf{m o l I}-1)$}

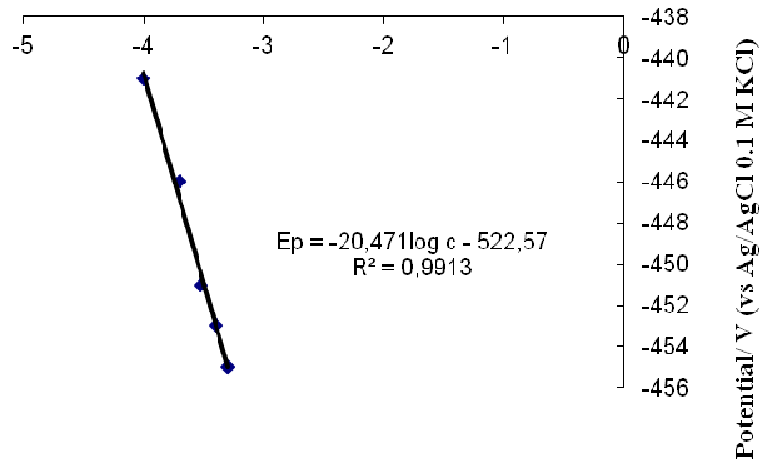

(b)

Figure 5. (a) Cyclic voltammograms of $\mathbf{1 d}$ at different concentration from $1 \times 10^{-4}-5 \times 10^{-4} \mathrm{M}$. (b) The plot of the peak potential vs. $\log c$ in $\mathrm{CH}_{3} \mathrm{CN}+0.1 \mathrm{M} \mathrm{Bu}_{4} \mathrm{NPF}_{6}$ at a platinum disk electrode $(\Phi=2 \mathrm{~mm})$. Scan rate $\mathrm{v}=50 \mathrm{mV} / \mathrm{s}$.
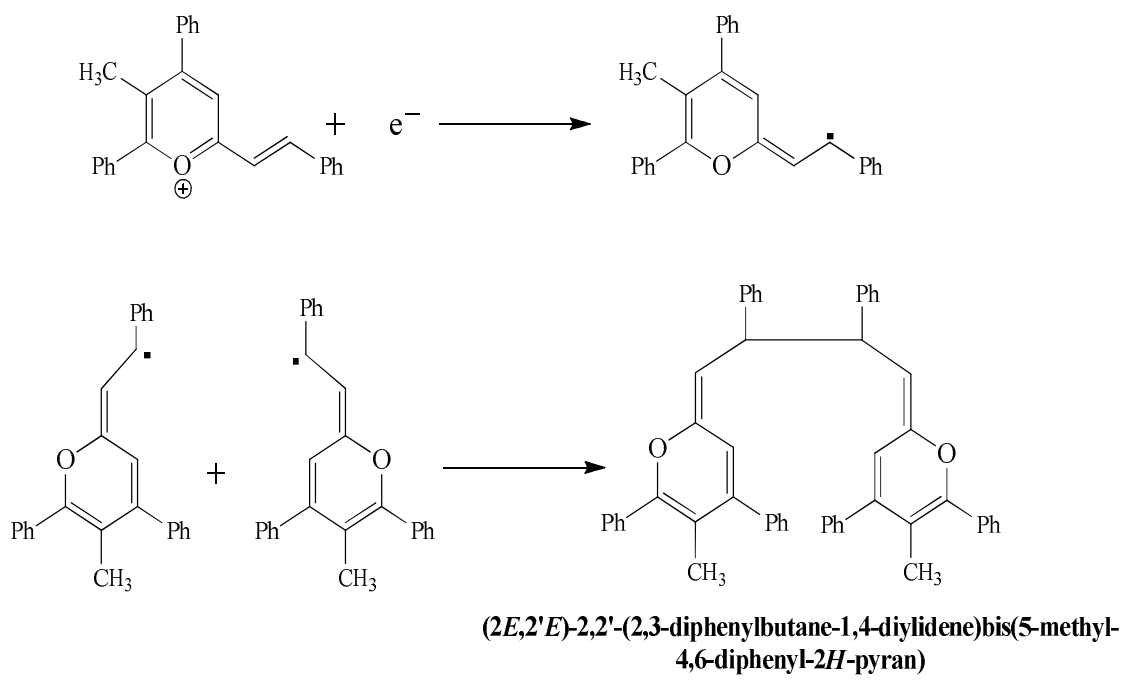

Scheme 2

\section{CONCLUSION}

In this work, five styrylpyrylium perchlorates were studied in a comparative electrochemical investigation. According to the cyclic voltammetry study of styrylpyrylium perchlorates, an electron-donating methyl group on the pyrylium ring leads to the shift towards cathodic values of the reduction potential. The styryl group's presence in the pyrylium ring leads to an anodic shift of the reduction peak potential. From kinetic investigations, the follow of the peak 
potential reduction upon scan rate and the substrate concentration of pyrylium salts demonstrated that irreversible reduction is under diffusion control and the charge transfer is

followed by a dimerization reaction between the radical pyranyl electrogenerated after the charge transfer.

\section{REFERENCES}

1. Bello, A.M.; Kotra, L.P. Tetrahedron Lett. 2000, 44, 9271.

2. Sib, S. Tetrahedron 1975, 31, 2229.

3. Leonard, K.A.; Nelen, M.I.; Anderson, L.T.; Gibson, S.L.; Hilf, R.; Detty, M.R. J. Med. Chem. 1999, 42, 3942.

4. Basting, D.; Schäfer, F.P.; Steyer, B. Appl. Phys. 1974, 3, 81.

5. Zhuang, J.Y.; Guo, J.Q.; Zhao, X.S. ; Liu, T.T. J. Phys. Chem. B 2000, 104, 5090.

6. Farcasiu, D.; Balaban, A.T.; Bologna, U.L. Heterocycles 1994, 37, 1165.

7. Komarova, E.Y.; Ren, K.; Neckers, D.C. Langmuir 2002, 18, 7753.

8. Miranda, M.A.; Galindo, F. ; Amat, A.M.; Aques, A. Appl. Catal. B. 2000, 28, 127.

9. Miranda, M.A.; Amat, A.M.; Aques, A. Catal. Today 2002, 76, 113.

10. Arques, A.; Amat, A.M.; Santos-Juanes, L.; Vercher, R.F.; Marı', M.L.; Miranda, M.A. Catal. Today 2009, 144, 106.

11. Kavarnos, G.J.; Turro, N.J. Chem. Rev. 1986, 86, 419.

12. Pragst, F.; Ziebig, R.; Seydewitz, U.; Driesel, G. Electrochim. Acta 1980, $25,341$.

13. Amatore, C.; Jutand, A.; Pflüger, F.; Jallabert, C.; Strzelecka, H.; Veber, M. Tetrahedron Lett. 1989, 30, 1383.

14. Klima, J.; Volke, J.; Urban, J. Electrochim. Acta 1991, 36, 73.

15. Wintgens, V.; Pouliquen, J.; Kossanyi, J. New J. Chem. 1986, 10, 345.

16. Tripathi, S.; Simalty, M.; Pouliquen, J.; Kossanyi, J. Bull. Soc. Chim. Fr. 1986, 4, 600.

17. Guel, B.; Tountian, C.D.; Bonzy-Coulibaly, Y.L.; Traoré, H.; Sib, F.S. C. R. Chimie 2007, $10,535$.

18. Simalty, M.; Carretto, J.; Sib, S. Bull. Soc. Chim. Fr. 1970, 11, 3920.

19. Hesse, K.; Hunig, S. Liebigs. Ann. Chem. 1985, 740.

20. Ouédraogo, J.C.W.; Tapsoba, E.; Sib, S.F.; Bonzi-Coulibaly, Y.L. Int. J. Spect. 2010, ID 246821.

21. Haouas Korbi, B.; Tapsoba, I.; Benkhoud, M.L.; Boujlel, K. J. Electroanal. Chem. 2004, $571,241$. 